\title{
HIGHLIGHT
}

\section{Combined pituitary hormone deficiency - lessons from the murine models}

\author{
Bu B Yeap and Peter J Leedman \\ Laboratory for Cancer Medicine and University Department of Medicine, Royal Perth Hospital, Perth, Western Australia, Australia \\ (Correspondence should be addressed to P J Leedman, University Department of Medicine, Royal Perth Hospital, Box X2213 GPO, \\ Perth WA 6001, Australia; Email: peterl@cyllene.uwa.edu.au)
}

\begin{abstract}
The molecular pathogenesis of some forms of combined pituitary hormone deficiency (CPHD, impaired production of growth hormone $(\mathrm{GH})$ and one or more of the other five pituitary hormones) was established with the discovery of mutations in the pituitary transcription factor, POU1F1 (the human homologue of mouse Pit1) several years ago (1). Pit-1 is a $33 \mathrm{kDa}$ pituitary-specific transcription factor present in somatotrophs, lactotrophs and thyrotrophs of the mature pituitary, the embryonal expression of which precedes that of GH and prolactin (PRL), but not thyroid-stimulating hormone (TSH) $\beta$. It is a member of the POU-domain protein family, possessing both a POU-specific and a POUhomeodomain region necessary for high-affinity binding to the promoter regions of GH and PRL genes (2). Pit-1 co-operates with E twenty-six specific oncogenerelated (Ets) transcription factors to regulate PRL gene expression (3), and with Zn-15 in the regulation of GH gene expression (4). In the thyrotroph, Pit-1 cooperates with activator protein-1-like (or GATA DNA-sequencespecific factor-2 (GATA-2)) factors to regulate $\mathrm{TSH} \beta$ gene expression (5).
\end{abstract}

As one might have predicted, elucidation of the genetics in murine models of dwarfism enabled linkage of a similar phenotype in man to mutations of Pit1. The Jackson dwarf mouse $(d w / d w J)$ has a major deletion in the Pit1 gene (6), whereas Snell dwarf mice possess the $d w / d w$ mutant Pit 1 allele that converts a tryptophan to cysteine (Trp-Cys) at amino acid 261 within the POU homeodomain (7). This mutation abolishes binding to a high-affinity Pit1-binding site, and is associated with deficiencies of GH, prolactin and TSH. Shortly thereafter, studies in a male patient with mental retardation, short stature, GH, PRL and TSH deficiency, but normal gonadotrophins and serum testosterone, identified a cytosine to thymine $(\mathrm{C}-\mathrm{T})$ mutation in POU1F1 that resulted in substitution of an arginine residue by tryptophan (Arg-Trp) at codon $271(1,8)$. This mutation inhibited transactivation from a GH promoter by the mutant gene product, and thyrotrophin-releasing hormone stimulation showed a blunted TSH response consistent with a pituitary defect. In two other separate families, children with a similar clinical phenotype were investigated. They presented with growth impairment,
GH and PRL deficiency, and either later onset or early postnatal central hypothyroidism. Affected members of one family were homozygous for a cytosine to guanosine (C-G) transition of POU1F1 that altered amino acid 158 from alanine to proline (Ala-Pro, A158P), whereas affected siblings of the second family were compound heterozygotes for A158P and a separate coding sequence deletion mutant (9).

These observations established a central role for mutations in POU1F1 in the molecular pathogenesis for many of the CPHD families, but left unresolved the nature of the genetic defect in those CPHD kindreds in which deficiency of gonadotrophins was also present. The recent cloning of the PROP1 (Prophet of Pit-1) gene has shed much light on the area. The human PROP1 gene (and the mouse homologue, Prop1) encodes a tissue-specific, paired homeodomain transcription factor expressed during embryonal pituitary development (10). Paired-class homeodomains bind as dimers to cognate DNA response elements containing TAAT palindromes, and the homeodomain region is highly conserved between human and mouse genes at both nucleotide and amino acid levels. Determination of the genetic defect in the Ames dwarf mouse proved to be very informative. These mice carry the $d f / d f$ allele, which has a serine to proline (Ser-Pro) mutation in the $\alpha 1$ helix of the PROP1 homeodomain, resulting in functional impairment of PROP1, near complete absence of somatotrophs, lactotrophs and thyrotrophs, and failure of activation of the Pit1 gene (10). In the embryonal pituitary, PROP1 expression precedes that of Pit 1 and, interestingly, the $d f / d f$ phenotype results from marked loss of Pit1 lineage cells and failure of Pit1 gene expression.

Interestingly, various different mutations in the human PROP1 gene have now been identified in patients with CPHD. In a study of non-related CPHD kindreds with GH, PRL and TSH deficiencies in whom POU1F1 alleles did not cosegregate with the CPHD phenotype, four kindreds with PROP1 mutations were identified. These were substitution of arginine to cysteine at codon 120 (R120C), a 2-bp deletion (301302delAG, two kindreds) and compound heterozygosity for the 2-bp mutation and a thymine to adenosine 
(T-A) transversion mutation at nucleotide 349 (resulting in substitution of phenylalanine to isoleucine at codon 117, F117I) (11). When tested in DNA-gel shift and reporter studies, these mutant PROP1 constructs exhibited absent or greatly reduced binding to the paired domain DNA consensus sequence, and either negligible or significantly reduced transactivation capacity (11). Further studies characterised the R120C mutation, in the third DNA-binding helix of the homeodomain, in affected siblings from two unrelated consanguineous families presenting with growth retardation. In the first family, all three affected siblings were homozygous for R120C, and displayed growth retardation around the age of 8 years and entered puberty having received GH treatment. However, gonadotrophin deficiency subsequently evolved to accompany the GH, PRL and TSH deficiencies present. In the second family, both affected siblings presented at or before 1 year of age (the first with central hypothyroidism), developed unequivocal GH, PRL and TSH deficiency, but retained measurable although decreased follicle-stimulating hormone (FSH) and luteinizing hormone (LH) responses (12). Thus the concomitant loss of FSH and LH support action of PROP1 in earlier pituitary progenitor cells, in addition to the failure of somatotroph, lactotroph and thyrotroph differentiation (13).

The 301-302delAG PROP1 mutation in exon 2 results in a coding sequence frameshift and premature termination at codon 109, predicting the loss of DNAbinding homeo- and C-terminal transactivation domains. This mutation has been identified in six of 10 probands from independent kindreds (five homozygous, one heterozygous) and three of 21 sporadic CPHD subjects (two and one respectively) (14). As the PROP1 sequence reads 295-CGAGAGAGTC-304, the 301302delAG mutation is identical to 296-297delGA, described in children with CPHD including complete GH and complete or partial PRL and TSH deficiencies, together with a 149-150delGA mutation (15). Studies on two other possibly related families with PROP1 deficiency have been published recently. Two siblings in one and six affected (of nine) siblings in the other family all had normal intelligence, short stature, immature facies and high pitched voices, with no signs of sexual maturation (ages 17.5-39.8 years). Serum GH after clonidine ingestion was extremely low as was insulin-like growth factor-I. PRL, free thyroxine, LH, FSH, testosterone and oestradiol concentrations were substantially reduced. Both pairs of parents were heterozygous and all eight affected individuals were homozygous for a GA or an AG deletion mutation in the sequence 296GAGAGAG in exon 2 of PROP1, confirming autosomal recessive inheritance and reinforcing the identity of this mutational 'hot-spot' (16).

It is clear that the clinical phenotype of mutations in PROP1 shares many features displayed by patients with mutations in the POU1F1 gene, as both develop deficiencies of GH, PRL and TSH. The major distinguishing feature of $\mathrm{CPHD}$ resulting from disruption of PROP1 function is a reduction in gonadotrophins, because deficiencies of LH/FSH are not observed in POU1F1 mutations. Interestingly, the clinical phenotype of CPHD differs between the various PROP1 gene mutations, and also between the affected siblings with the same mutation in the same family (12). The reasons for these differences remain to be elucidated. However, future studies that characterise the biological factors responsible for development of these differing phenotypes will be of great interest.

\section{References}

1 Radovick S, Nations M, Du Y, Berg La VA, Weintraub BD \& Wondisford FE. A mutation in the POU-homeodomain of Pit-1 responsible for combined pituitary hormone deficiency. Science $19922571115-1118$.

2 de la Hoya M, Vila V, Jimenez O \& Castrillo JL. Anterior pituitary development and Pit-1/GHF-1 transcription factor. Cellular Molecular Life Science 199854 1059-1066.

3 Bradford AP, Wasylyk C \& Gutierrez-Hartmann A. Interaction of Ets-1 and the POU-homoedomain protein GHF-1.Pit-1 reconstitues pituitary-specific gene expression. Molecular and Cellular Biology 199717 1065-1074.

4 Lipkin SM, Naar Am, Kalla KA, Sack RA \& Rosenfeld MG. Identification of a novel zinc finger protein binding a conserved element critical for Pit-1-dependent growth hormone gene expression. Genes and Development 19937 1674-1687.

5 Gordon DF, Lewis SR, Haugen BR, James RA, McDermott MT, Wood WM et al. Pit-1 and GATA-2 interact and functionally cooperate to activate the thyrotropin beta-subunit promoter. Journal of Biological Chemistry 1997272 2433924347.

6 Behringer RR, Mathews LS \& Palmiter RD. Dwarf mice produced by genetic ablation of growth hormone-expressing cells. Genes and Development 19882 453-461.

7 Li S, Crenshaw EB, Rawson EJ, Simmons DM, Swanson LW \& Rosenfeld MG. Dwarf locus mutants lacking three pituitary cell types result from mutations in the POU-domain gene pit-1. Nature 1990347 528-533.

8 Cohen LE, Wondisford FE, Salvatoni A, Maghnie M, BruckerDavis F, Wientraub BD et al. A 'hot spot' in the Pit-1 gene is responsible for combined pituitary hormone deficiency: clinical and molecular correlates. Journal of Clinical Endocrinology and Metabolism $199580679-684$.

9 Pfaffle RW, DiMattia GE, Parks JS, Brown MR, Wit JM, Jansen M et al. Mutation of the POU-specific domain of Pit-1 and hypopituitarism without pituitary hypoplasia. Science 1992257 1118-1121.

10 Sornson MW, Wu W, Dasen JS, Flynn SE, Norman DJ, O'Connell SM et al. Pituitary lineage determination by the Prophet of Pit-1 homeodomain factor defective in Ames dwarfism. Nature 1996 $384327-333$.

11 Wu W, Cogan JD, Pfaffle RW, Dasen JS, Frisch H, O’Connell SM et al. Mutations in PROP1 cause familial combined pituitary hormone deficiency. Nature Genetics 199818 147-149.

12 Fluck C, Deladoey J, Rutishauser K, Eble A, Marti U, $\mathrm{Wu} \mathrm{W}$ et al. Phenotypic variability in combined pituitary hormone deficiency caused by a PROP1 gene mutation resulting in the substitution of Arg-Cys at codon 120 (R120C). Journal of Clinical Endocrinology and Metabolism 199883 3727-3734.

13 Watkins-Chow DE \& Camper SA. How many homeobox genes does it take to make a pituitary gland? Trends in Genetics 199814 284-290. 
14 Cogan JD, Wu W, Phillips JA III, Arnhold JP, Agapito A, Fofanova OV et al. The PROP1 2-base pair deletion is a common cause of combined pituitary hormone deficiency. Journal of Clinical Endocrinology and Metabolism 199883 3346-3349.

15 Fofanova O, Takamura N, Kinoshita E, Parks JS, Brown MR, Peterkova VA et al. Compound heterozygous deletion of the PROP1 gene in children with combined pituitary hormone deficiency. Journal of Clinical Endocrinology and Metabolism 1998 83 2601-2604.

16 Rosenbloom AL, Almonte AS, Brown MR, Fisher DA, Baumbach L \& Parks JS. Clinical and biochemical phenotype of familial anterior hypopituitarism from mutation of the PROP1 gene. Journal of Clinical Endocrinology and Metabolism 199984 $50-57$. 